\title{
Comparison of the measurement and effects of habitat structure on gastropods in rocky intertidal and mangrove habitats
}

\author{
MichaeI W. Beck*** \\ Institute of Marine Ecology, A11, University of Sydney, New South Wales 2006, Australia
}

\begin{abstract}
Ecologists have had little success in the development of a synthetic understanding of the effects of habitat structure on species, because structural complexity is measured differently in most studies and habitats. There were 3 main objectives of this study: (1) to measure and compare structural complexity between rocky intertidal and mangrove habitats, (2) to examine whether structural complexity affected the density, richness and size of gastropods in these habitats, and (3) to determine whether one index of structural complexity [e.g. fractal dimension (D) and chain-and-tape] best represented features of the habitat that affected gastropods. I used photogrammetric techniques to measure and to compare the effects of structural complexity in quadrats (1 $\mathrm{m}$ apart) nested withn sites $(10 \mathrm{~m}$ apart), shores ( $>1 \mathrm{~km}$ apart) and habitats (rocky intertidal and mangrove) in Botany Bay, Australia. All indices showed that complexity was different between quadrats just meters apart in both habitats and was greater in mangrove than in rocky intertidal habitats. Two lines of evidence indicated that variation in complexity affected the density of gastropods in rocky intertidal but not in mangrove habitats. First, the density of gastropods varied 4-fold between quadrats within habitats and, after gastropods were experimentally removed, a similar density and size distribution of gastropods recolonized quadrats in the rocky intertidal. Second, this density was correlated with structural complexity. $D$ was most often correlated with density and thus best represented features of the habitat that affected gastropods. The measurement and effects of structural complexity can be compared between habitats, and these comparisons help elucidate the conditions in which habitat structure may exert strong effects on species.
\end{abstract}

KEY WORDS: Habitat structure - Fractal dimension - Rocky intertidal - Mangrove - Field experiment

\section{INTRODUCTION}

It is well known that the structures in many habitats (e.g. forests, coral reefs, rocky intertidal, mangrove) have a strong influence on the diversity and abundance of species (e.g. Grinnell 1917, Gause 1934, Crisp \& Barnes 1954, Huffaker 1958, Connell 1961, Emson \& Faller-Fritsch 1976, Keough \& Downes 1982, Fletcher \& Underwood 1987, Walters \& Wethey 1996). Ecologists have, however, had little success in the development of a synthetic understanding of the effects of

\footnotetext{
·E-mail:mbeck@bio.usyd.edu.au

- Present address: Coastal and Marine Program, The Nature Conservancy, 88 First Street, Suite 600, San Francisco, California 94105, USA
}

habitat structure on populations or communities (Dean \& Connell 1987, McCoy \& Bell 1991), because there is little consistency in the definition and measurement of habitat structure in studies within or between habitats (McCoy \& Bell 1991).

Habitat structure has at least 3 major elements: structural complexity, heterogeneity and scale (McCoy $\&$ Bell 1991). Structural complexity, the focus of this study, represents variation in habitat structure attributable to the abundance of individual structural components (McCoy \& Bell 1991). Structural components are distinct physical elements of the habitat, e.g. rocks, trees, pits, or pneumatophores (McCoy \& Bell 1991, Downes et al. 1998). Structural complexity has been called many names (e.g. topographic complexity, rugosity, substrate heterogeneity), but even when the 
same element of habitat structure is defined and studied, there is little consistency in its measurement. The lack of commensurability in the measurement of structural complexity (and thus habitat structure) makes it difficult to interpret the results of prior studies and to use them to develop new hypotheses about the effects of habitat structure on species.

One solution to this problem of commensurability is to find and to use indices of structural complexity that are comparable within and between habitats (Sanson et al. 1995). Many indices could be used to compare structural complexity within habitats if they were used consistently (e.g. density of pits or percent cover of vegetation). A smaller subset of indices may be useful for examining the effects of structural complexity on species within and between habitats. These latter indices include the fractal dimension $(D)$, vector dispersion (VD), consecutive substratum height difference $\left(\Sigma \mathrm{dh}^{2}\right)$ and chain-and-tape (Chain).

A major purported strength of these latter indices is their comparability in different habitats (e.g. McCoy \& Bell 1991, Gee \& Warwick 1994a, Sanson et al. 1995), but there are no direct comparisons between habitats. Indices have been compared within habitats to determine which index best identified features of the habitat that appeared to be related to the density of species

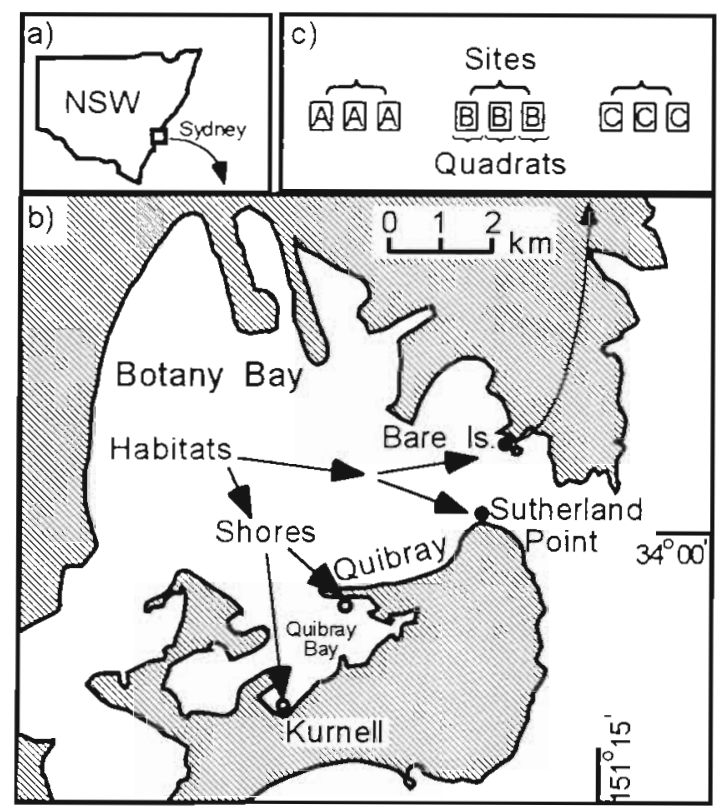

Fig. 1. Botany Bay (b) in New South Wales (a), Australia, showing habitats and shores used in the study. For the sampling design (c) used on each shore, each quadrat was $0.61 \times$ $0.41 \mathrm{~m}$, and quadrats were $1 \mathrm{~m}$ apart. Sites contained 3 quadrats and were $10 \mathrm{~m}$ apart. This sampling design could not be used on Kurnell in the comparisons of structural complexity, but was used in the recolonization experiments on all shores (see text) (e.g. Stoner \& Lewis 1985, Underwood \& Chapman 1989, McCormick 1994. Hills \& Thomason 1996, Jacobi \& Langevin 1996)

An important consideration in the measurement of structural complexity is the interval or scale of measurement (McCoy \& Bell 1991). Apparent structural complexity should depend on the size of the organism, but most indices are only calculated at 1 interval. One of the suggested advantages of $D$ is that it includes assessment of structural complexity across a range of intervals that may be relevant to the organisms in question (Morse et al. 1985, Williamson \& Lawton 1991, Kostylev et al. 1997). It is, however, possible and practical to calculate most indices at several intervals to examine the size-specific effects of structural complexity (e.g. Carleton \& Sammarco 1987, Sanson et al. 1995, Beck 1997a).

Ultimately, to understand the conditions under which habitat structure affects the density and diversity of species, it will be essential to interpret the measurement and effects of structural complexity between different studies and habitats. To address this issue, I measured several indices of structural complexity in different quadrats (1 $\mathrm{m}$ apart), sites (10 $\mathrm{m}$ apart), shores (>1 km apart) and habitats (rocky intertidal and mangrove) in Botany Bay, Australia. I determined whether these indices identified differences in structural complexity within and between habitats. I then did recolonization experiments to investigate whether gastropods could respond to differences in structural complexity. Finally, I examined correlations between the indices of structural complexity and gastropod density and richness to determine which index best represented features of the habitat that affected gastropods.

\section{METHODS}

Natural history of habitats and organisms. All observations and experiments were done in Botany Bay, Australia, at 2 rocky intertidal and 2 mangrove shores (Fig. 1). The study areas on the 2 rocky intertidal shores, Bare Island and Sutherland Point (Fig. 1), were on moderately sheltered, mid-shore sandstone rock benches (e.g. Underwood 1975a, b, Underwood \& Chapman 1996). The rocks appeared to be mostly bare with some encrusting algae; there were no foliose macroalgae. The main structural components on these broad flat benches were shallow pits that were often hemispherical ( 5 to $60 \mathrm{~mm}$ deep). The study areas on the 2 intertidal mangrove shores, Kurnell and Quibray (Fig. 1), were within the region bounded by the grey mangrove Avicennia marina tree line (landward) and the beginning of the Zostera capricornii seagrass beds (seaward). This region is mid to low shore and has muddy sediments with few or no oysters (Underwood \& Barrett 1990). The main 
structural components were pneumatophores (10 to $110 \mathrm{~mm}$ in height), the arial roots of the mangroves.

In the study areas on these shores, gastropods were the only animals larger than $5 \mathrm{~mm}$ that were directly associated with the surfaces of the habitat. Three herbivorous species were common (>90\% of individuals in the study areas) in each habitat. In the rocky intertidal, the limpet Cellana tramoserica and the snails Bembicium nanum and Austrocochlea porcata (ex. constricta) (Underwood 1975a, b) were abundant, and in the mangrove the snails Velacumantus australis, Bembicium auratum and A. porcata (Chapman \& Underwood 1995) were abundant. A. porcata was the only species that occurred in both habitats. These habitats and gastropods are common around Sydney (e.g. Hutchings \& Saenger 1987, Crowe 1996, Underwood \& Chapman 1996).

Comparison of structural complexity within and between habitats. I used photogrammetric techniques (e.g. Fryer 1983, Warren \& Underwood 1986) to measure structural complexity. In March 1996, I sampled nine $0.25 \mathrm{~m}^{2}$ quadrats on each shore along a haphazardly placed, $22 \mathrm{~m}$ transect run parallel to the tide line. The quadrats were clumped in groups of 3 at $10 \mathrm{~m}$ intervals, hereafter referred to as sites (Fig. 1). It was not possible to conform exactly to this design at Kurnell in the first survey, because the quadrats were moved along the transect to avoid pools of standing water that could not be drained. Photogrammetry is difficult between 2 mediums.

In each $0.25 \mathrm{~m}^{2}$ quadrat, I removed and measured all the gastropods and then took a stereophoto of the quadrat. Stereophoto pairs were analyzed on an MPS-2 photogrammetric system (Adam Technology, Bentley, Western Australia). Ten $300 \mathrm{~mm}$ long transects were sampled randomly for each quadrat, and the topography (i.e. height) was recorded at $5 \mathrm{~mm}$ intervals along each transect (Fig. 2).

Four indices of structural complexity were calculated from each $300 \mathrm{~mm}$ transect: $D$, VD, $\Sigma \mathrm{dh}^{2}$ and Chain (Fig, 2). D is a measure of the decrease in apparent length of the transect (i.e. habitat) as the interval of measurement is increased. $D$ was calculated by the dividers method (Sugihara \& May 1990). The relationship between apparent length and divider interval was estimated over the range 5 to $35 \mathrm{~mm}$ at each whole number interval (i.e. 5, 6, 7, ., 34, $35 \mathrm{~mm}$ ) and examined for linearity before estimating $D$ with ordinary least squares (OLS) regression (Fig. 2c). This range was chosen because the finest resolution of this photogrammetric analysis was $5 \mathrm{~mm}$ and more than $99 \%$ of gastropods were $35 \mathrm{~mm}$ or smaller in both habitats. VD is a measure of angular variance and was calculated with a 2-dimensional modification of the formula in Carleton \& Sammarco (1987). $\Sigma \mathrm{dh}^{2}$ was calculated as the sum of squared differences in height from one point to the next (MCCormick 1994). The Chain index was calculated as the ratio of the apparent distance to linear distance (Connell \& Jones 1991, Beck 1997a) (Fig. 2b).

$D$ is calculated explicitly across several size classes or intervals, but the other indices usually are calculated at only 1 interval (e.g. Luckhurst \& Luckhurst 1978, McCormick 1994). I calculated the other indices first at the finest resolution, $5 \mathrm{~mm}$. At this resolution, the indices are most likely to identify differences in structural complexity among habitats. Features of the habitat that most affect indices at $5 \mathrm{~mm}$ (e.g. small pits) might, however, not affect gastropods. Therefore, I also calculated

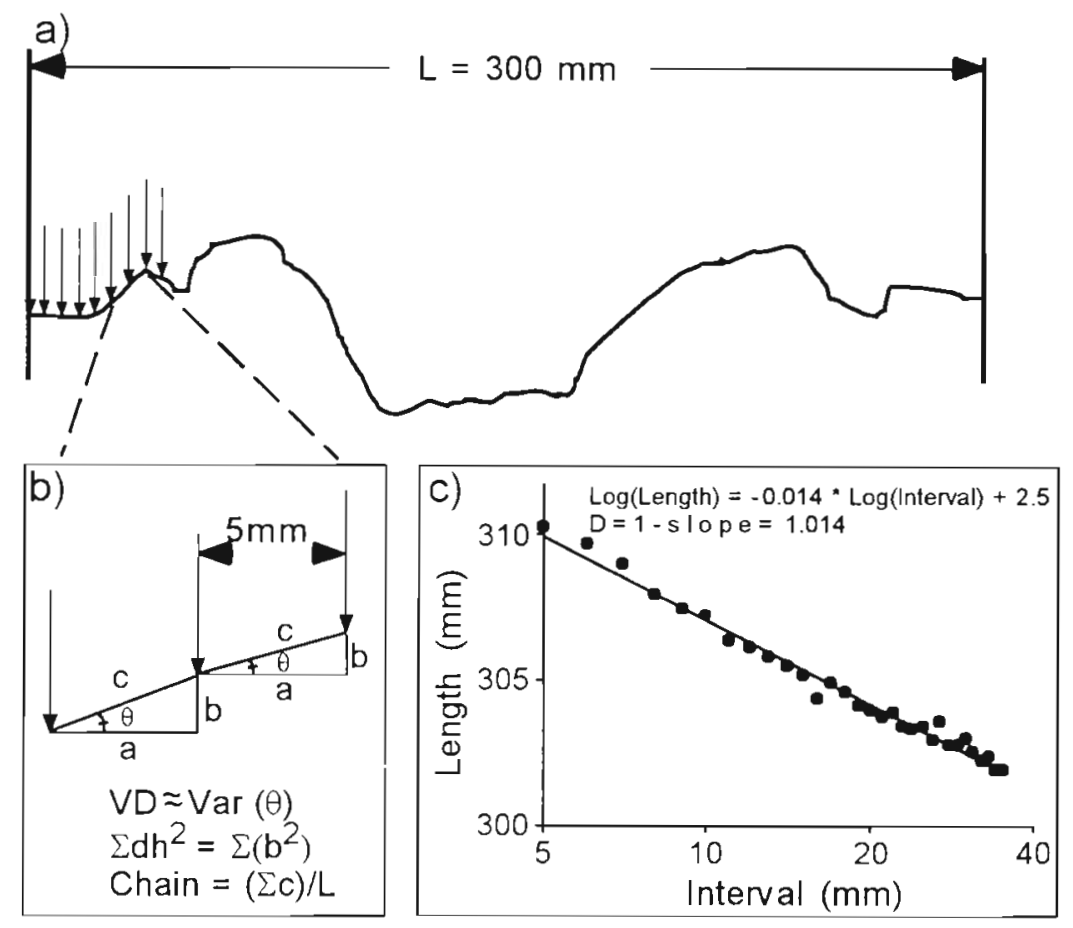

Fig. 2. Measurement of the indices of structural complexity |fractal dimension (D), vector dispersion (VD), consecutive substratum height difference $\left(\Sigma \mathrm{dh}^{2}\right)$ and chain-and-tape (chain). (a) Transect through quadrat showing profile of the habitat. (b) Illustration of the calculation of $\mathrm{VD}, \Sigma \mathrm{dh}^{2}$ and Chain at the $5 \mathrm{~mm}$ interval. $V D$ is a measure of the variance in $\theta ; V D=\left\{n-\left[\sum_{1}^{n}(a / c)\right\}\right\} /(n-1)$, $\mathrm{n}$ is the number of separate triangles along the transect. (c) Illustration of the calculation of $D$ by the dividers method. Points are the apparent length of the transect measured by 'dividers' of increasingly greater intervals. The equation for the line and the calculation of $D$ are shown 
VD, $\Sigma \mathrm{dh}^{2}$ and Chain at $10,15,20,25$ and $30 \mathrm{~mm}$ intervals for comparisons against abundance of gastropods.

A general and useful index of structural complexity should be able to identify differences in structural complexity within and between habitats. To determine whether these indices could identify differences in structural complexity among quadrats, sites, shores and habitats, 2 sets of fully hierarchical (nested) ANOVAs were done. In the first set of analyses, 3-way ANOVAs were done to examine variability in each index $\left(D, V D, \Sigma \mathrm{dh}^{2}\right.$ and Chain) among quadrats, shores, and habitats. The factor site could not be included, because there were not distinct sites at Kurnell (see above). Quadrats (random factor) were nested within shores (random) nested within habitats (fixed). There was missing data for 1 quadrat at Kurnell. To balance the ANOVA, I replaced these data with values averaged from the 8 other quadrats at Kurnell and subtracted the appropriate df from the quadrat (1 df) and residual effects (9 df) (Underwood 1997). All data in ANOVAs were examined for heteroscedasticity with Cochran's $C$-test, and if necessary the data were transformed to meet assumptions. Multiple comparisons were done with Student-Newman-Keuls (SNK) tests (Underwood 1997). For all analyses, mean square values were obtained from SA.S (Release 6.04, SAS Institute Inc., Cary, NC, USA), and mean square estimates were calculated as in Winer et al. (1991).

The second set of analyses was done so that variability among sites (random) could be examined, and therefore I could not include the data at Kurnell. Comparisons of structural complexity were done for the 2 rocky shores combined in a 3-way hierarchical design: quadrats within sites within shores. The structural complexity data from Quibray were analyzed alone in a 2-way hierarchical design (i.e. without a shore effect).

Recolonization experiments: gastropod responses to the habitat. If quadrat-specific (intrinsic) properties of the habitat affected gastropods (and structural complexity is just 1 possible property), I predicted (1.) that the density, richness and size of gastropods should vary between quadrats and (2) that if I experimentally removed gastropods from quadrats, the density, richness and size of gastropods that recolonized the quadrat should be similar to that prior to removal. On each shore, all the gastropods were removed from nine $0.25 \mathrm{~m}^{2}$ quadrats, identified to species, and the maximum lengths of their shells were recorded. The gastropods were moved $5 \mathrm{~m}$ downshore to make it unlikely that individuals could return to specific quadrats. The quadrats were resurveyed after at least 2 mo, and the density and size of gastropods was measured. Only gastropods $\geq 5 \mathrm{~mm}$ were included in the statistical analyses, because this was the smallest interval at which structural complexity was measured.
This experiment was repeated 3 separate times in 1996 (March-May, May-September, SeptemberDecember) on the rocky intertidal shores in the same quadrats where topography was measured (Fig. 1). The quadrats were marked for re-sampling by scoring the rock lightly with a knife at 2 comers.

The recolonization experiments were done once on the mangrove shores; gastropods were measured and removed from quadrats in September and re-examined in December 1996. It was not possible to do these experiments in the same quadrats where topography was measured, because those quadrats were marked inadequately and could not be relocated. It was, however, possible in this experiment to adhere to the sampling design illustrated in Fig. 1 on both mangrove shores, and therefore to examine gastropod responses between quadrats and sites. The quadrats in the mangrove were marked at 2 corners with thin metal stakes with flagging tape attached for this experiment.

Densities were examined before removal and after recolonization in 4-way repeated measures ANOVAs within each habitat for each experiment. There were repeated measurements of abundance in quadrats within sites within shores over time (fixed factor). In this analysis there are only 2 levels of time in each experiment, therefore sphericity is not a problem (Huynh \& Feldt 1970). Repeated measures analyses can still be problematic, because it is assumed that the highest level interaction \{i.e. time $\times$ quadrat [site (shore)]\} is not significant, and this assumption cannot be evaluated (Underwood 1997). To address this problem and to provide another test of the predictions, I also examined the product-moment correlation of density between times and assessed whether the results from the ANOVAs and the correlations were consistent. The lack of a significant time effect (i.e. statistically similar densities between times) in the ANOVA and a significant positive correlation in density before removal and after recolonization would indicate that gastropod density was affected by quadrat-specific properties of the habitat.

I also examined correlations in density before removal and after recolonization for each of the 3 most abundant species to determine whether any of the individual species were affected strongly by quadratspecific properties of the habitat. Finally, I examined correlations in species richness and in average size of gastropods before removal and after recolonization to examine whether these variables were affected by quadrat-specific properties of the habitat. Some of these correlations were examined graphically, and I used OLS regression to illustrate the linearity of the association. The regression lines are only used for reference; no special significance is attached to the particular slopes. 
If the size distributions (not just average size) of gastropods were affected by quadrat-specific properties of the habitat, the size distributions should be more similar within quadrats between times (before removal and after recolonization within quadrats) than between quadrats within times. The size distributions were compared with Kolmogorov-Smirnov 2-sample tests (K-S D) (Sokal \& Rohlf 1981) within quadrats between times ( $\mathrm{n}=9$ per shore) and then between quadrats within times ( $n=72$ per shore; i.e. 36 possible comparisons at each time: quadrat 1 vs 2,1 vs $3 \ldots 8$ vs 9). I then compared the number of non-significant $K-S D$ values within quadrats between times (i.e. observed similarity) to the number of non-significant $\mathrm{K}-\mathrm{S} D$ values of size distributions between quadrats within times (i.e. expected similarity) by $\chi^{2}$-test.

Comparisons between indices of structural complexity and gastropod density and richness. If structural complexity affects gastropods, there should be correlations between the indices of structural complexity and gastropod density and richness. Moreover, the index with the most significant correlations should provide the best representation of the structural complexity of the habitat that is relevant to gastropods. Correlations were used to assess the association between variables, and OLS regressions were used for graphical comparisons. Data for comparisons between structural complexity and gastropod density and richness were only available for 1 time period on the mangrove shores, but data from 4 different sampling periods were available on the rocky intertidal shores (see previous section).

\section{RESULTS}

\section{Comparison of structural complexity within and between habitats}

It was possible to use photogrammetry to measure and compare the indices of structural complexity within and between habitats. $D$ could be estimated, because the log apparent distance vs log interval relationships were linear (e.g. $64 \%$ of rocky intertidal transects had $r>0.95,66 \%$ of mangrove transects had $r>0.89$ ), and they were significantly different from zero.

All indices revealed significant differences in structural complexity between quadrats within shores and between habitats (Table 1). There was significant heteroscedasticity in all 4 indices of structural complexity: variances were always much greater on mangrove shores than on rocky intertidal shores (Fig. 3). No transformation ameliorated this problem, but the balanced ANOVA can be robust to heteroscedasticity (Underwood 1997). Structural complexity was consistently greater on the mangrove shores than on the rocky intertidal shores (Table 1, Fig. 3). There also were significant differences in all indices among quadrats within shores and habitats (Table 1); i.e. structural complexity varied among quadrats. There were no differences in indices of structural complexity between the rocky intertidal shores, but all indices except $\Sigma \mathrm{dh}^{2}$ revealed differences in structural complexity between the mangrove shores (Table 1, Fig. 3).

ANOVAs for each index also revealed that variation in complexity was always greater between quadrats meters apart than between sites tens of meters apart on the rocky intertidal shores and on Quibray (i.e. significant effects of quadrat but not site; Table 2).

\section{Recolonization experiments: gastropod responses to the habitat}

\section{Rocky intertidal shores}

On the rocky intertidal shores, properties of the habitat affected the density of gastropods. Quadrats just meters apart differed in density, and when gastropods were experimentally removed from quadrats, the density of recolonizers was similar. Variation in the density

Table 1. Nested ANOVAs to compare the 4 indices of structural complexity [(fractal dimension (D), vector dispersion (VD), consecutive substratum height difference $\left(\Sigma \mathrm{dh}^{2}\right)$, chain-and-tape (Chain)] within and between habitats. The degrees of freedom for Quadrat and Residual have been reduced to account for missing replicates (see 'Methods'). In the F-ratios, the mean square of Habitat is tested over Shore(Habitat), which is tested over Quadrat[Shore(Habitat)], which is tested over the Residual. Significance: $p<0.05, \cdots p<0.01, \cdots p<0.001$; ns: nonsignificant $(p>0.05)$

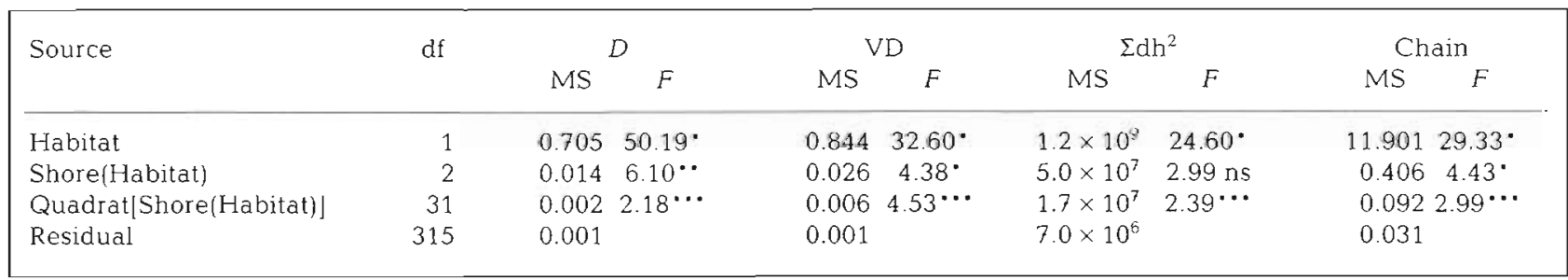




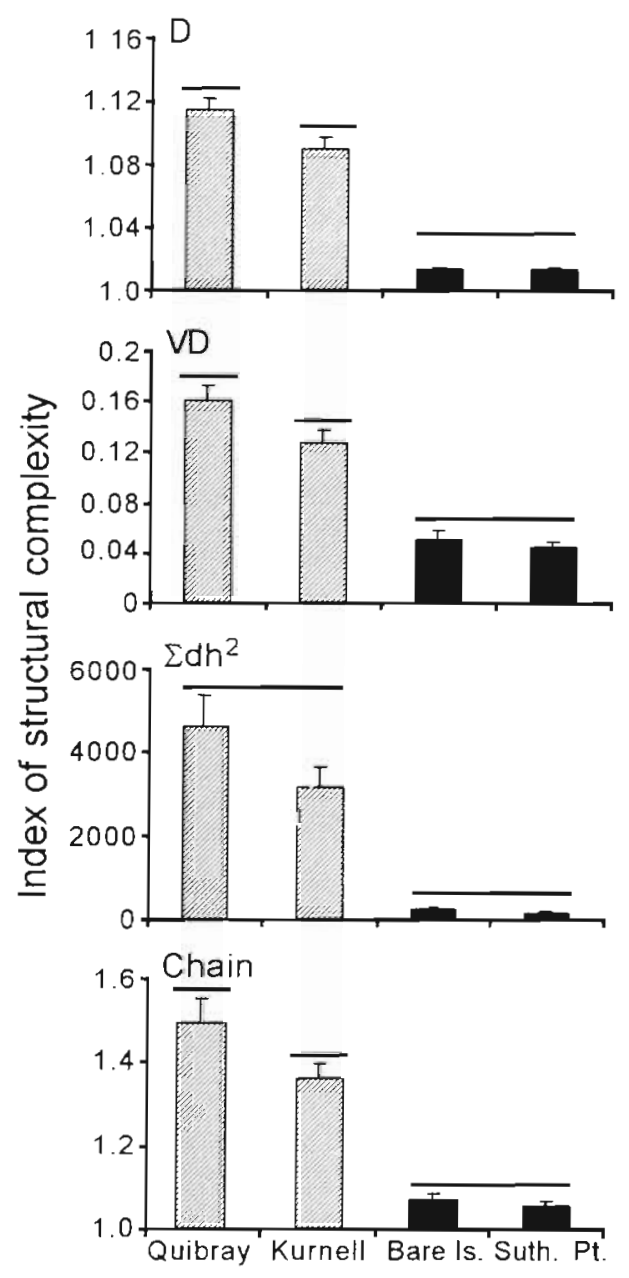

Fig. 3. Comparison of indices of structural complexity between habitats and shores. All indices revealed significant differences in structural complexity between habitats. Lines connected over bars indicate statistical similarity in the indices of complexity. Values are mean \pm 1 SE. By definition, $D$ varies between 1 and 2 , and Chain must be $\geq 1.0$. For all indices, greater values indicate greater structural complexity Bars for the mangrove shores are hatched. Suth. Pt. = Sutherland Point

of gastropods was as great or greater among quadrats meters apart than among sites tens of meters apart (i.e. no significant effect of site; Table 3a). The density of gastropods within quadrats was similar before removal and after recolonization (i.e. no significant effect of time) in all 3 of the experiments (Table 3a). These results were corroborated by the significant correlations in the density of gastropods within quadrats before removal and after recolonization in Expts 2 and 3 on Bare Island ( $r=0.79$ and 0.87 , respectively, $d f=7, p<0.01$ ) and in all 3 experiments on Sutherland Point ( $r=0.92$, 0.97 and 0.78 , respectively, $\mathrm{df}=7, \mathrm{p}<0.01$ ) (Fig. $4 \mathrm{a}, \mathrm{b}$ ). In Expt 1 on Bare Island there was a positive correlation in density between times, but it was not significant ( $\mathrm{r}=$ 0.62, df =7, $p=0.08$ ) (Fig. 4a).
In Expt 1 there was a significant time by shore interaction in the comparison of the density of gastropods before removal and after recolonization (Table 3a). The source of this interaction effect is indicated in Fig. 4a, b; density generally decreased between removal and recolonization on Bare Island, but it generally increased on Sutherland Point.

Of the 3 most abundant gastropod species, Bembicium nanum had the strongest response to properties of the habitat. The density of $B$. nanum was correlated positively in quadrats before removal and after recolonization in each experiment on both shores (i.e. 6 of 6 correlations significant). The abundance of Cellana tramoserica was correlated positively before removal and after recolonization in Expts 1 \& 2 on both shores, but not in Expt 3 (i.e. 4 of 6 correlations significant). The abundance of Austrocochlea porcata was correlated positively before removal and after recolonization only in Expt 1 at Bare Island and in Expt 2 on Sutherland Point (i.e. 2 of 6 correlations significant).

The average size of gastropods in rocky intertidal quadrats varied nearly 2 -fold but was highly correlated before removal and after recolonization on both shores for all 3 experiments (Bare Island: $r=0.81,0.79$ and 0.67 , respectively, $\mathrm{df}=7, \mathrm{p}<0.05$; Sutherland Point: $\mathrm{r}=0.98$, 0.93 and 0.92 , respectively, $\mathrm{df}=7, \mathrm{p}<0.001$ ) (Fig. 5a, b).

The size distributions of gastropods on these shores, however, were non-normal (Fig. 6a, b); therefore, I also examined the size distributions of gastropods before removal and after recolonization. These tests indicated that similar size distributions of gastropods returned to quadrats after removal in 1 of 3 experiments on Bare Island and in all 3 experiments on Sutherland Point. On Bare Island, size distributions were more similar within quadrats before removal and after recolonization (K-S $D$ showed that 8 of 9 size distributions were similar within quadrats between times) than between quadrats within times ( 31 of 72 size distributions were similar between quadrats within times) in Expt $1\left(\chi^{2}=\right.$ 7.73, df $=1, \mathrm{p}<0.01$ ). In Expts 2 and 3 the size distributions of gastropods were no more similar within quadrats between times than between quadrats within times $\left(\chi^{2}=2.02\right.$ and 0.25 , respectively, $\left.d f=1, p>0.05\right)$. On Sutherland Point, the size distributions were more similar within quadrats between times than expected in all 3 experiments (Expt 1: $\chi^{2}=8.67$, df $=1, \mathrm{p}<0.01$; Expt 2: $\chi^{2}=3.46, \mathrm{df}=1, \mathrm{p}=0.06$, Expt $3: \chi^{2}=8.67, \mathrm{df}=$ $1, \mathrm{p}<0.01$ ).

Species richness was low in most quadrats (Bare Island, 1 to $6 \mathrm{spp}$. per quadrat; Sutherland Point, 1 to 4 spp. per quadrat) and did not appear to be affected strongly by quadrat-specific properties of the habitat. Species richness was not significantly correlated before removal and after recolonization in any of the 3 experiments on Bare Island $(r=0.26,0.29$ and 0.46 , 
Table 2. Nested ANOVAs to compare the 4 indices of structural complexity (D, VD, $\Sigma \mathrm{dh}^{2}$, Chain) within habitats. (a) Rocky intertidal shores. In the F-ratios, the mean square of Shore is tested over Site(Shore), which is tested over Quadrat:[Site (Shore)], which is tested over the Residual. (b) Quibray only. In the F-ratios, the mean square of Site is tested over Quadrat(Site), which is tested over the Residual. Significance: $\cdot p<0.05, \cdots p<0.01, \cdots p<0.001$, ns: nonsignificant $(p>0.05)$

\begin{tabular}{|c|c|c|c|c|c|c|c|c|c|}
\hline \multirow[t]{2}{*}{ Source } & \multirow[t]{2}{*}{$d f$} & \multicolumn{2}{|c|}{$D$} & \multicolumn{2}{|c|}{ VD } & \multicolumn{2}{|c|}{$\Sigma d h^{2}$} & \multicolumn{2}{|c|}{ Chain } \\
\hline & & MS & $F$ & MS & $F$ & MS & $F$ & MS & $F$ \\
\hline \multicolumn{10}{|c|}{ (a) Rocky intertidal shore } \\
\hline Shore & 1 & 0.0001 & $0.08 \mathrm{~ns}$ & 0.0021 & $0.67 \mathrm{~ns}$ & $2.2 \times 10^{5}$ & $0.96 \mathrm{~ns}$ & 0.0073 & $0.89 \mathrm{~ns}$ \\
\hline Site(Shore) & 4 & 0.0001 & $0.88 \mathrm{~ns}$ & 0.0031 & $0.94 \mathrm{~ns}$ & $2.3 \times 10^{5}$ & $1.15 \mathrm{~ns}$ & 0.0082 & $1.04 \mathrm{~ns}$ \\
\hline Quadrat [Site(Shore)] & 12 & 0.0002 & $6.00^{\cdots}$ & 0.0033 & $11.86^{\cdots}$ & $2.0 \times 10^{5}$ & $6.86^{\cdots}$ & 0.0079 & $11.40^{\cdots}$ \\
\hline Residual & 162 & 0.0001 & & 0.0003 & & $2.9 \times 10^{4}$ & & 0.0007 & \\
\hline \multicolumn{10}{|l|}{ (b) Quibray } \\
\hline Site & 2 & 0.0074 & $1.51 \mathrm{~ns}$ & 0.0075 & $0.60 \mathrm{~ns}$ & $8.7 \times 10^{7}$ & $2.36 \mathrm{~ns}$ & 0.3689 & $1.61 \mathrm{~ns}$ \\
\hline Quadrat(Site) & 6 & 0.0049 & $2.52^{\circ}$ & 0.0126 & $5.38 \cdots$ & $3.7 \times 10^{7}$ & $2.30^{\circ}$ & 0.2298 & $3.66^{\circ}$ \\
\hline Residual & 81 & 0.0019 & & 0.0023 & & $1.6 \times 10^{7}$ & & 0.0629 & \\
\hline
\end{tabular}

Table 3. Repeated-measures ANOVAs to compare density of gastropods in quadrats before removal and after recolonization within habitats. (a) Rocky intertidal shores: 3 separate experiments. (b) Mangrove shores. In the F-ratios for all analyses, the mean square of Shore is tested over Site(Shore), which is tested over Quadrat[Site(Shore)]. The mean square of Time is tested over Time $\times$ Shore, which is tested over Time $\times$ Site(Shore), which is tested over Time $\times$ Quadrat[Site (Shore)]. The test of Time is the comparison of density before removal and after recolonization within quadrats. Significance: $p<0.05, \cdots p<0.01, \cdots p<$ 0.001, ns: nonsignificant $(\mathrm{p}>0.05$ )

\begin{tabular}{|c|c|c|c|c|c|c|c|}
\hline \multirow[t]{2}{*}{$\begin{array}{l}\text { (a) Rocky intertidal shores } \\
\text { Source }\end{array}$} & \multirow[t]{2}{*}{ df } & \multicolumn{2}{|c|}{ Expt 1} & \multicolumn{2}{|c|}{ Expt 2} & \multicolumn{2}{|c|}{ Expt 3} \\
\hline & & MS & $F$ & MS & $F$ & MS & $F$ \\
\hline Shore & 1 & 7773 & $5.99 \mathrm{~ns}$ & 9637 & $6.72 \mathrm{~ns}$ & 3136 & $1.38 \mathrm{~ns}$ \\
\hline Site(Shore) & 4 & 1298 & $1.89 \mathrm{~ns}$ & 1433 & $1.13 \mathrm{~ns}$ & 2276 & $1.49 \mathrm{~ns}$ \\
\hline Quadrat[Site(Shore)] & 12 & 685 & & 1273 & & 1525 & \\
\hline Time & 1 & 97 & $0.44 \mathrm{~ns}$ & 67 & $2.91 \mathrm{~ns}$ & 128 & $0.09 \mathrm{~ns}$ \\
\hline Time $\times$ Shore & 1 & 220 & $9.19^{\circ}$ & 23 & $0.32 \mathrm{~ns}$ & 1393 & $2.71 \mathrm{~ns}$ \\
\hline Time $\times$ Site $($ Shore $)$ & 4 & 24 & $0.21 \mathrm{~ns}$ & 72 & $1.03 \mathrm{~ns}$ & 514 & $2.23 \mathrm{~ns}$ \\
\hline Time $\times$ Quadrat[Site(Shore)] & 12 & 116 & & 70 & & 230 & \\
\hline (b) Mangrove shores & & & & & & & \\
\hline Source & df & MS & $F$ & & & & \\
\hline Shore & 1 & 4853 & $2.32 \mathrm{~ns}$ & & & & \\
\hline Site(Shore) & 4 & 2094 & $1.37 \mathrm{~ns}$ & & & & \\
\hline Quadrat[Site(Shore)] & 12 & 1527 & & & & & \\
\hline Time & 1 & 12769 & $4.02 \mathrm{~ns}$ & & & & \\
\hline Time $\times$ Shore & 1 & 3173 & $5.03 \mathrm{~ns}$ & & & & \\
\hline Time $\times$ Site $($ Shore $)$ & 4 & 631 & $0.86 \mathrm{~ns}$ & & & & \\
\hline Time $\times$ Quadrat[Site(Shore)] & 12 & 737 & & & & & \\
\hline
\end{tabular}

respectively, $d f=7, p>0.05)$. On Sutherland Point species richness was correlated before removal and after recolonization during Expt $1(\mathrm{r}=0.85, \mathrm{df}=7, \mathrm{p}<0.01)$ but not during Expts 2 or $3(r=0.25$ and -0.13 , respectively, $\mathrm{df}=7, \mathrm{p}>0.05$ ).

\section{Mangrove shores}

On the mangrove shores, properties of the habitat had weak or no effects on the density and size of gastropods. The ANOVAs indicated that the density of gastropods in quadrats was similar before removal and after recolonization (i.e. no significant effect of time; Table $3 b)$. There was, however, no correlation in abundance before removal and after recolonization on Kurnell or Quibray ( $\mathrm{r}=0.31$ and 0.63 , respectively, $\mathrm{df}=7$, $\mathrm{p}>0.05$ ) (Fig. 4c)

When the densities of the 3 most abundant species, Austrocochlea porcata, Bembicium auratum and Velacumantus australis, were compared within quadrats before removal and after recolonization there were no significant correlations at Kurnell $(r=0.09,0.53$ and 0.34 , respectively, $\mathrm{df}=7, \mathrm{p}>0.05$ ). At Quibray, the 


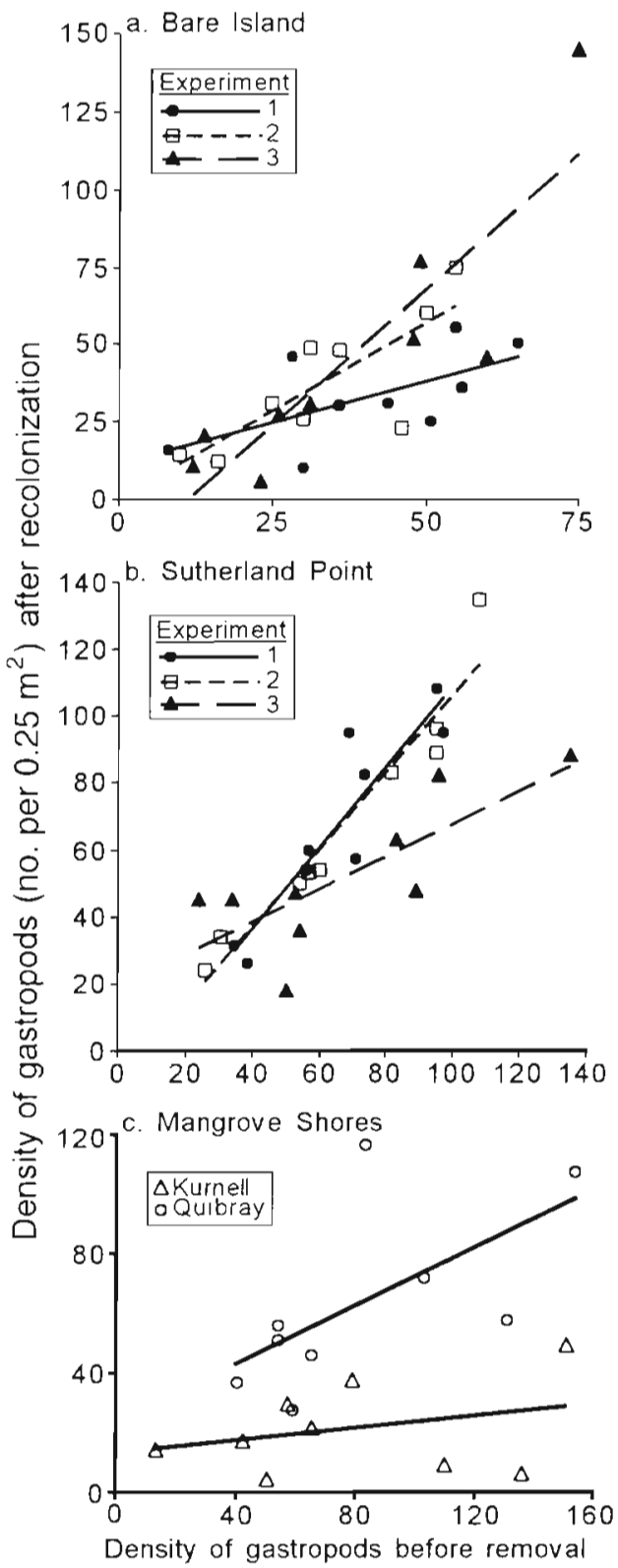

Fig. 4. Density of gastropods in quadrats before removal and after recolonization. (a, b) Rocky intertidal shores; Expt $1(\bullet)$, solid line; Expt 2 (a), short dash; Expt 3 (4), long dash. All the correlations on rocky intertidal shores were significant $(p<$ $0.01)$, except on Bare Island in Expt $1(p=0.08)$. (c) Mangrove shores: Kurnell $(\Delta)$, Quibray (o). Correlations on Kurnell and. Quibray were not significant

densities of $A$. porcata and $B$. auratum were positively correlated before removal and after recolonization ( $\mathrm{r}=$ 0.85 and 0.71 , respectively, $\mathrm{df}=7, \mathrm{p}<0.05$ ), but the density of $V$. australis was not $(r=0.04, \mathrm{df}=7, \mathrm{p}>0.05)$.

The average size of gastropods was correlated before removal and after recolonization at Kurnell ( $\mathrm{r}=$ 0.76 , df $=7, p<0.05$ ) but not at Quibray ( $r=0.01$, df $=$ 7. $\mathrm{p}>0.05$ ) (Fig, 5c). The size distributions on both

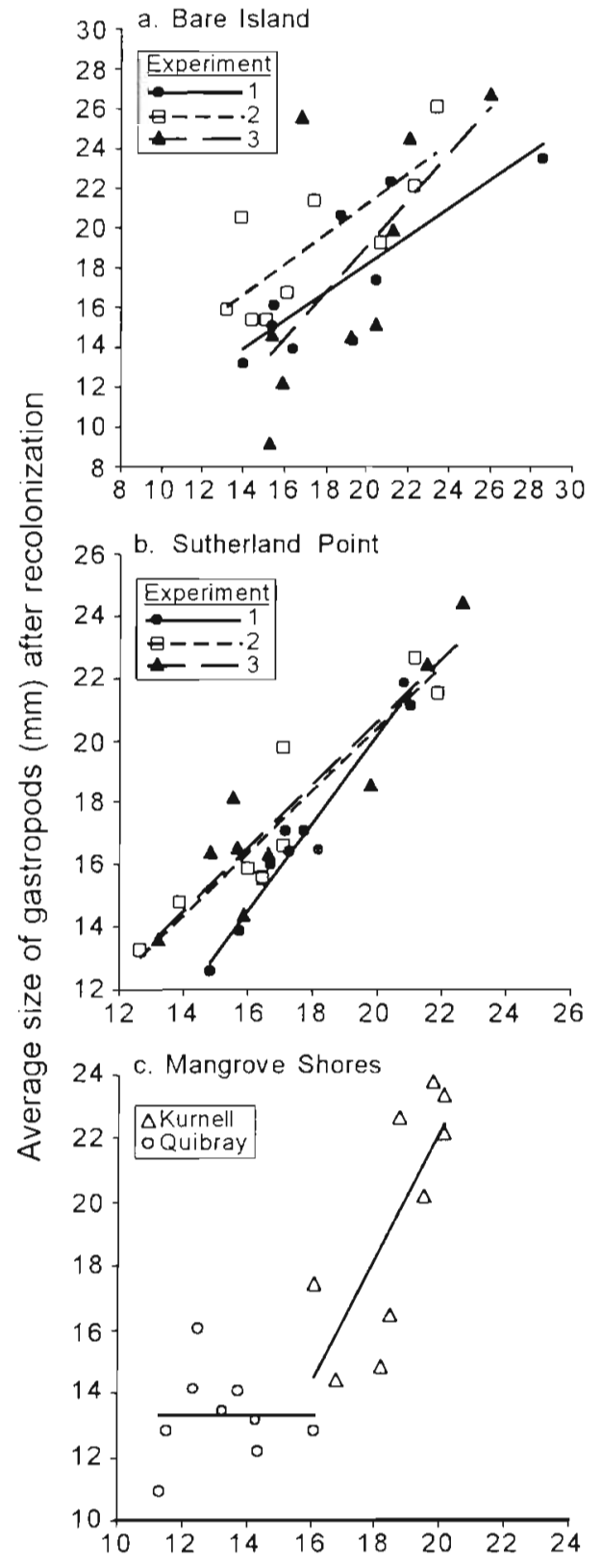

Avg size of gastropods $(\mathrm{mm})$ before removal

Fig. 5. Average size of gastropods in quadrats before removal and after recolonization. $(a, b)$ Rocky intertidal shores: Expt 1 (•), solid line, Expt 2 (a), short dashi Expt 3 (4), long dash. (c) Mangrove shores: Kurnell ( $\Delta)_{i}$ Quibray (o). The average size of gastropods was correlated at Kurnell but not at Quibray

shores, however, were non-normal (Fig. 6c, d). There was no evidence that similar size distributions of gastropods returned to mangrove quadrats after removal; on both shores size distributions were no more similar within quadrats between times than between quadrats within times (Kumell $\chi^{2}=0.84$; Quibray $\chi^{2}=0.01$; $\mathrm{df}=$ $1, \mathrm{p}>0.05$ for both locations). 
Fig. 6. Size-frequency distributions. $(a, b)$ Rocky intertidal shores. Data are from all gastropods collected across 4 sampling times (Bare Island $n=1425$, Sutherland Point $n=2289$ ). (c, d) Mangrove shores. Data are from all gastropods collected across 3 sampling times (Kurnell $\mathrm{n}=1671$, Quibray $\mathrm{n}=$ 1681). The last bar for Kurneli and for Quibray is all individuals $\geq 39 \mathrm{~mm}$
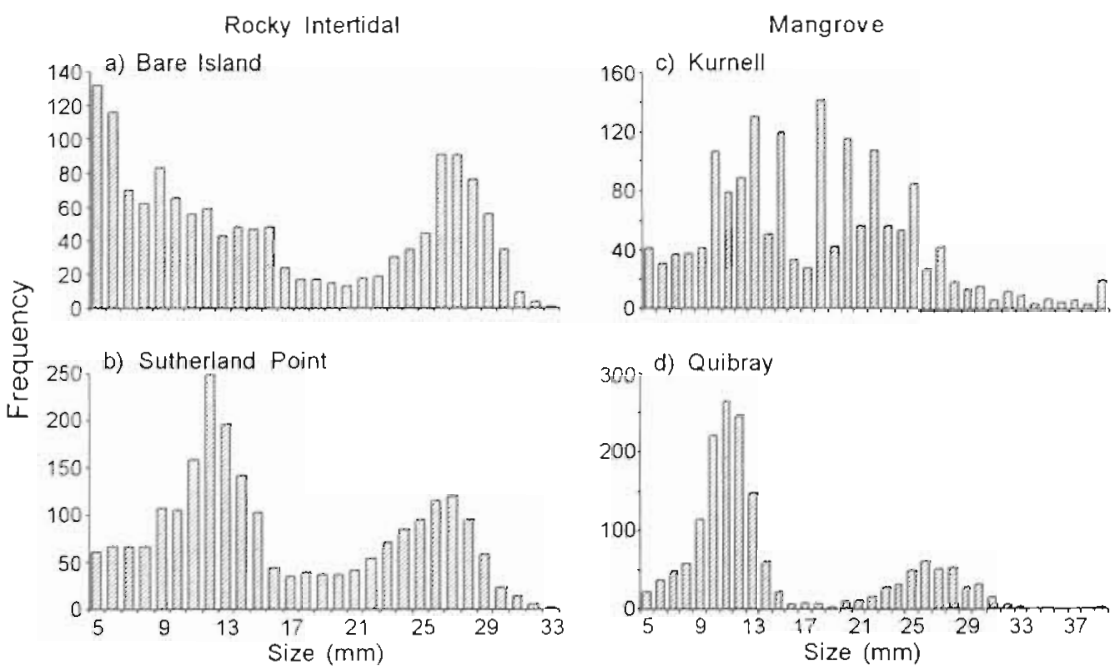

Species richness was low in most quadrats (Kurnell, 2 to $8 \mathrm{spp}$. per quadrat; Quibray, 2 to $6 \mathrm{spp}$. per quadrat) and did not appear to be affected by quadratspecific properties of the habitat. Species richness was not significantly correlated before removal and after recolonization at either Kurnell $(\mathrm{r}=-0.016, \mathrm{df}=6, \mathrm{p}>$ $0.05)$ or Quibray $(\mathrm{r}=0.36 \mathrm{df}=7, \mathrm{p}>0.05)$.

\section{Comparison between indices of structural complexity and gastropod density and richness}

\section{Rocky intertidal shores}

On the rocky intertidal shores, the density of gastropods appeared to be affected by structural complexity, and $D$ had more significant correlations with the density of gastropods than other indices (Table $4 \mathrm{a}$, Fig. 7 a). When the data on the shores were combined, $D$ was the only index correlated with the density of gastropods, and it was correlated at all times (Table 4 a).

Calculation of VD, $\Sigma d h^{2}$ and Chain at intervals (10, $15,20,25$, or $30 \mathrm{~mm}$ ) other than $5 \mathrm{~mm}$ did not improve the correlations between these indices and the density of gastropods. The density of gastropods was compared on each of the 4 sample dates for the shores alone and combined against indices calculated at the 5 larger intervals (i.e. 60 correlations for each index, 180 total), and only one of these correlations was significant. For these indices the finest resolution ( $5 \mathrm{~mm}$ ) generally provided the best representation of features of the habitat that may affect gastropods, but they still were not as highly correlated with gastropod density as $D$.

Of the 3 most common species, Bembicium nanum appeared to be most affected by structural complexity, and $\mathrm{D}$ was the index most consistently and positively correlated with its abundance (Table 5). There were few correlations between the indices of structural complexity and the abundances of Cellana tramoserica or Austrocochlea porcata (Table 5).

On Bare Island, species richness was correlated with the indices of structural complexity at only one time (all indices fourth sample date, $\mathrm{p}<0.05$ ) and on Sutherland Point there were no significant correlations between richness and structural complexity at any time.

\section{Mangrove shores}

There were no significant correlations on either mangrove shore between any index of structural complexity and the density of gastropods (Table $4 \mathrm{~b}$, Fig $7 b, c)$. There also were no significant correlations between the indices of structural complexity and the densities of the 3 most abundant gastropod species on either shore. When the interval of measurement of VD, $\Sigma \mathrm{dh}^{2}$ and Chain was increased, there was only 1 significant correlation with the density of gastropods and only when the data from the shores were combined ( $\mathrm{I}=$ -0.49 , df $=15, p<0.05$ for $V D$ at $10 \mathrm{~mm}$ ). There were no significant correlations between species richness and any index of structural complexity on either Kurnell or Quibray.

\section{DISCUSSION}

The results illustrated several important points: (1) structural complexity can be compared between habitats, (2) structural complexity appeared to affect 
Table 4. Correlations between indices of structural complexity and gastropod density. (a) Number of significant correlations (p < 0.05 ) on rocky intertidal shores from the 4 separate dates on which gastropods were sampled. Values of the correlation coefficients are given in parentheses. For rocky shores alone $\mathrm{df}=7$, and when data from shores are combined df $=16$. (b) Correlation coefficient for mangrove shores. There is only 1 sample of density of gastropods on each shore, and the value of the correlation coefficlent is indicated. For Kurnell df $=6$, for Quibray df $=7$, and when shores were combined df $=15$ No correlations on mangrove shores were significant

\begin{tabular}{|c|c|c|c|}
\hline $\begin{array}{l}\text { (a) Rocky intertidal shores } \\
\text { Index }\end{array}$ & Bare Jsland & Sutherland Point & Shores combined \\
\hline$D$ & $\begin{array}{c}2 \\
(0.51,0.68,0.74,0.58)\end{array}$ & $(0.68,0.69,0.67,0.38)$ & $\begin{array}{c}4 \\
(0.48,0.49,0.57,0.48)\end{array}$ \\
\hline VD & $(0.65,0.62,0.72,0.44)$ & $\begin{array}{c}0 \\
(0.56,0.65,0.59,0.23)\end{array}$ & $\begin{array}{c}0 \\
(0.37,0.31,0.40,0.36)\end{array}$ \\
\hline$\Sigma \mathrm{dh}^{2}$ & $\begin{array}{c}0 \\
(0.61,0.55,0.59,0.24)\end{array}$ & $\begin{array}{c}0 \\
(0.49,0.56,0.49,0.16)\end{array}$ & $\begin{array}{c}0 \\
(0.26,0.14,0.23,0.19)\end{array}$ \\
\hline Chain & $(0.64,0.59,0.69,0.36)$ & $\begin{array}{c}0 \\
(0.52,0.59,0.52,0.18)\end{array}$ & $\begin{array}{c}0 \\
(0.31,0.22,0.32,0.29)\end{array}$ \\
\hline $\begin{array}{l}\text { (b) Mangrove shores } \\
\text { Index }\end{array}$ & Kurnell & Quibray & Shores combined \\
\hline $\begin{array}{l}D \\
V D \\
\Sigma d^{2} \\
\text { Chain }\end{array}$ & $\begin{array}{r}-0.23 \\
-0.30 \\
0.05 \\
-0.04\end{array}$ & $\begin{array}{l}0.34 \\
0.31 \\
0.43 \\
0.39\end{array}$ & $\begin{array}{l}-0.36 \\
-0.39 \\
-0.17 \\
-0.26\end{array}$ \\
\hline
\end{tabular}

the density of gastropods in rocky intertidal but not mangrove habitats, (3) $D$ best represented features that affected gastropods in rocky intertidal habitats, (4) variability in structural complexity and density of gastropods was as great between quadrats as between sites in both habitats and (5) these indices help elucidate the conditions in which habitat structure may exert strong effects on species. These points are illustrated succinctly in Fig. 7, and they are handled in depth and in turn below

\section{Photogrammetry and structural complexity}

Photogrammetry can be used to measure structural complexity within and between rocky intertidal, mangrove, and other habitats from microscopic to landscape levels. It is relatively easy and quick to do in the field and only moderately time consuming in the lab. Other techniques can be tedious and time consuming (e.g. Sun et al. 1993, author's personal experience). Photogrammetry has the added benefit of preserving a permanent record of the quadrats. In this study, the indices were calculated in 2 dimensions to ensure that all indices were commensurable, and these may be sufficient for most considerations of structural complexity (Sanson et al. 1995, Hills \& Thomason 1996). In contrast to most other methods, however, the data are entered and preserved explicitly in 3 dimensions.
Table 5. Number of significant correlations ( $d f=7, p<0.05$ ) between the indices of complexity and the density of the 3 most common gastropods on rocky intertidal shores. There were a total of 8 comparisons between each index and the density of gastropods ( 4 sample dates on each of the 2 shores). All correlations were positive except for 2 correlations between the indices and the density of Cellana tramoserica

\begin{tabular}{|lccc|}
\hline Index & $\begin{array}{c}\text { Bembicium } \\
\text { nanum }\end{array}$ & $\begin{array}{c}\text { Cellana } \\
\text { tramoserica }\end{array}$ & $\begin{array}{c}\text { Austrocochlea } \\
\text { porcata }\end{array}$ \\
\hline$D$ & 7 & 2 & 0 \\
$V D$ & 2 & 0 & 1 \\
$\sum \mathrm{dh}^{2}$ & 2 & 1 & 1 \\
Chain & 1 & 0 & 1 \\
\hline
\end{tabular}

\section{Gastropod responses to the habitat}

Two lines of evidence indicated that structural complexity affected the density of gastropods in the rocky intertidal habitat. First, when gastropods were experimentally removed from quadrats which varied in density by 4 -fold, a similar density and size distribution of gastropods recolonized the quadrats. Second, this density was correlated with structural complexity at 4 different times of year. These results are consistent with. results of prior studies which indicate that the structural complexity of aquatic rocky habitats can affect the density of gastropods (e.g Emson \& Faller-Fritsch 1976, Raffaelli \& Hughes 1978, Fairweather 1988, 


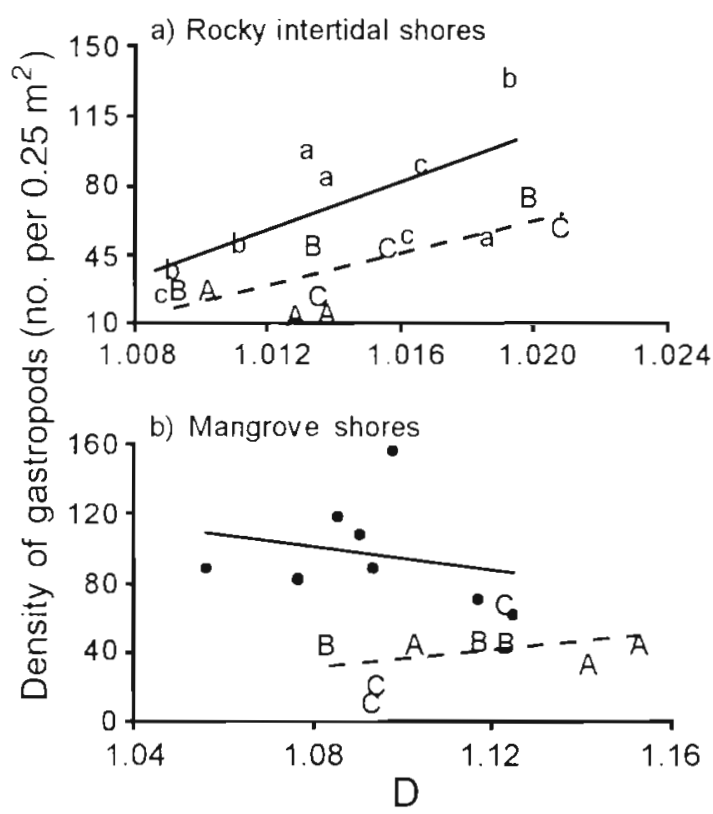

Fig. 7 Association between the density of gastropods and $D$. (a) Rocky intertidal shores: Bare Island = capital letters, dashed line; Sutherland Point = small letters, solid line. Data are shown from just the third sampling date. Density of gastropods was significantly correlated with $D$ on each rocky intertidal shore alone and when the data were combined (b) Mangrove shores: Kurnell (•), solid line; Quibray = capital letters, dashed line. Density was not correlated with $D$ on ether mangrove shore or when the data were combined. The matching letters within (a) and (b) represent the 3 quadrats of each site (as in Fig. 1c). Variation in complexity and gastropod density were as great between quadrats within sites (with same letter code) as between sites (i.e. quadrats within sites are not clumped on either axis). Quadrats at Kurnell do not have letter codes, because the sampling design shown in

Fig. 1c could not be used in this analysis (see 'Methods')

Kostylev et al. 1997) and other animals (e.g. Hart 1978, Keough \& Downes 1982, Walters \& Wethey 1996 , Downes et al. 1998). Species richness of gastropods did not appear to be affected strongly by quadrat-specific properties of rocky intertidal habitats.

Bembicium nanum showed the strongest response to the habitat in the recolonization experiments, and its density was correlated with structural complexity at all but one time on both shores. The other abundant species, Cellana tramoserica and Austrocochlea porcata, only appeared to be affected by structural complexity at a few times and places. The limpet, C. tramoserica, may not be affected strongly by structural complexity, because it can clamp tightly to flat rock surfaces to avoid the effects of desiccation stress, wave surge or predators. Some types of structural complexity, e.g. small pits, may interfere with attachment and feeding of C. tramoserica (Keough et al. 1997). McGuinness \& Underwood (1986) also found that $B$. nanum was affected positively by structural complexity, but $A$. por- cata was not. They suggested that the response of $B$. nanum may be related to the avoidance of physical stress (e.g. desiccation and wave surge).

On the mangrove shores, gastropods rarely showed strong, quadrat-specific responses the to habitat, and density and richness were not correlated with the indices of structural complexity. These data suggest that structural complexity had little effect on the distribution of these gastropods. The recolonization experiments indicated, however, that some property of the habitat on Quibray affected the densities of Bembicium auratum and Austrocochlea porcata. Several prior studies found that oysters and pneumatophores affected the abundance of $B$. auratum on mangrove shores in temperate Australia, and the complexity of these structural components was implicated as an important factor (Branch \& Branch 1980, Underwood \& Barret 1990). In the only direct examination, manipulation of complexity had no effect on the growth of $B$. auratum (Kaly 1988).

\section{Usefulness of $D$ (and other indices)}

All of the indices identified differences among quadrats within shores and between rocky intertidal and mangrove habitats. The main features in these habitats were pits and pneumatophores, respectively, and the indices measured the abundance and size of these features differently (Fig. 2). $D$ was the index most consistently correlated with the density of gastropods in the rocky intertidal habitat, where structural complexity appeared to affect gastropods. $D$ may best represent the features that affect these gastropods, because it measures the structural complexity of pits across multiple intervals or scales (e.g. Kostylev et al. 1997). Most other indices do not account for the potential size-specific effects of structural complexity on species. Even for specific size classes within species, the effects of structural complexity are likely to be important at more than just one scale le.g Bourget et al. 1994, Lemire \& Bourget 1996).

Some of these indices have been compared in other studies. McCormick (1994) concluded that $\Sigma \mathrm{dh}^{2}$ was the best among 6 indices (Chain, VD, $\Sigma d h^{2}$, another VD-like index and 2 other $\Sigma d h^{2}$-like indices) at describing habitat features that affected reef fish. Carleton \& Sammarco (1987) compared 6 indices of structural complexity (VD, vector strength, average surface angle and 3 measures related to deviations from a plane) and found that most were correlated with the density and diversity of coral spat at settlement. Underwood \& Chapman (1989) concluded that VD was better than 2 other indices (Chain and a VD-like index) at separating amongst rocky intertidal structural com- 
ponents. VD was not, however, correlated with the density of the gastropod Littorina unifasciata, despite the fact that prior experiments suggested properties of the habitat affected the density of L. unifasciata (Underwood \& Chapman 1989, 1992). Their results imply a conclusion similar to the one I reach: VD may identify differences in structural complexity in the habitat, but it may not measure features that affect gastropods.

There is substantial confusion in the relationship between indices and structuraI complexity, which contributes to the unfortunate tendency to classify indices like those examined here as mathematical or geostatistical in opposition to other indices that are purportedly 'biologically meaningful' (e.g. Hills \& Thomason 1996). These 'biologically meaningful' indices, e.g. surface area (SA) or number of pits, are presumed to be useful even when there is little direct evidence that they represent features of the habitat that affect the species in question. It is inappropriate to assume a priori that one index, e.g. SA, is different or better than other indices of complexity (e.g. Hart 1978, Jeffries 1993). SA could not be measured in this study, but the Chain index effectively estimates the perimeter of the habitat and should be closely related to SA.

It has also been argued that condensing complexity into single measures (e.g. D) may lead to a great loss of information (Simberloff et al. 1987). This problem is important, but it is valid for all indices of structural complexity (e.g. number of pits is a singular measure). The use of indices is not meant to preclude the examination of the mechanisms underlying responses of species to habitat structure (e.g. Beck 1995, 1997a).

In these rocky intertidal and mangrove habitats, $D$ could not be related to the body-size distribution of gastropods. Several studies have suggested that $D$ may be correlated with. the descending (or right-hand) slope of the body-size distribution (Morse et al. 1985, Gunnarsson 1992, Gee \& Warwick 1994a, b) in what has been termed a 'fractal explanation of body-size distribution' (Shorrocks et al. 1991). It was not possible to estimate this descending slope of the size distributions of gastropods, because the distributions were multimodal (Fig. 6). Loder et al. (1997) argued that many body-size distributions will be multimodal and the location of the modes will depend on the size classes that are chosen to create the distributions. These problems make it difficult to test the relationship between $D$ and the body-size distribution.

\section{Variation in topography and abundance within habitats}

In the rocky intertidal and the mangrove habitats, variation in complexity and abundance of gastropods was generally as great or greater between quadrats within meters of one another than between sites tens of meters apart. This high variation at the smallest distances is not consistent with most considerations of spatial variability, which is generally considered to increase the farther apart the samples are taken (e.g Williamson \& Lawton 1991, Bell et al. 1993). Only 2 distances were examined explicitly here, but Underwood \& Chapman (1996) examined variability in the densities of gastropod and barnacle species between quadrats from centimeters to tens of kilometers apart on rocky intertidal shores around Sydney. They found that variability in the density of gastropods was highest among nearby or contiguous quadrats. The substantial variation in complexity documented in the present study in quadrats meters apart could contribute to the pattern in variability of density documented in Underwood \& Chapman (1996).

\section{Use of indices in the development of hypotheses}

The greatest potential benefit of these indices is that they enable direct comparisons between different studies and habitats, which helps to elucidate the general conditions under which structural complexity has strong effects on the density and diversity of species. For example, the present observations and experiments suggest that structural complexity is more likely to affect the distribution of gastropods in the rocky intertidal than in the mangrove habitat. Structural complexity, however, was much greater in the mangrove than in the rocky intertidal habitat, and many studies suggest that there may be threshold levels above which changes in structural complexity have no effect on species (see Heck \& Crowder 1991). Species richness of gastropods did not appear to be affected by structural complexity in either habitat, which suggests that in general structural complexity may have a greater effect on density than diversity. It is possible to manipulate structural complexity to test predictions from these hypotheses.

These comparative observations and experiments also help to identify why gastropods might respond to structural complexity (e.g Crowe 1996). Gastropods may respond to structural complexity because it provides refuge from biological (e.g. predators, competitors) or physical factors (e.g wave surge, desiccation). These latter factors should be examined first because apparent differences in physical factors were consistent with differences in response to structural complexity between habitats. Wave surge and desiccation can have strong effects in rocky intertidal habitats (e.g. Moran 1985), but they are not likely to exert strong effects in mangrove habitats. Mangrove shores are sheltered, and the muddy substrates are rarely dry 
Competitors and predators can affect gastropods in both habitats (e.g. Underwood 1978, 1984, Branch \& Branch 1980), which suggests that they are less likely than physical factors to explain why there were differences in the effects of structural complexity between habitats

Experiments are required to determine how and why animals respond to structural complexity, and they may show that these responses are species-, quadrat-, size- and time-specific (e.g. Underwood \& Chapman 1992, Beck 1995, 1997 a, Walters \& Wethey 1996). This proposed variability cannot be an argument against conducting these experiments in the first place (Beck $1997 \mathrm{~b}$ ). Experiments to examine some of the hypotheses proposed here are in progress.

Acknowledgements. This work was supported by a Fulbright Fellowship and an ARC Postdoctoral Research Fellowship. I thank T Glasby, J. Harris and V. Matthews for fleld assistance. This paper benefited from extensive discussions and reviews by M. J. Anderson, T. Glasby, M. Haddon, B. Kelaher and A. J. Underwood

\section{LITERATURE CITED}

Beck MW (1995) Size-specific shelter limitation in stone crabs: a test of the demographic bottleneck hypothesis. Ecology 76:968-980

Beck MW (1997a) A test of the generality of the effects of shelter bottlenecks in four stone crab populations. Ecology 78 : 2487.2503

Beck MW (1997b) Inference and generality in ecology: current problems and an experimental solution. Oikos 78 : 265-273

Bell G, Lechowicz MJ, Appenzeller A, Chandler M, DeBlois E, Jackson L, Mackenzie B, Preziosi R, Schallenberg M, Tinker $N$ (1993) The spatial structure of the physical environment. Oecologia (Berl) 96:114-121

Bourget E, Deguise J, Daigle G (1994) Scales of substratum heterogeneity, structural complexity, and the early establishment of a marine epibenthic community. J Exp Mar Biol Ecol 181:31-51

Branch GM, Branch ML (1980) Competition in Bembicium auratum (Gastropoda) and its effect on microalgal standing stock in mangrove muds. Oecologia (Berl) 46:106-114

Carleton JH, Sammarco PW (1987) Effects of substratum irregularity on success of coral settlement: quantification by comparative geomorphological techniques. Bull Mar Sci 40:85-98

Chapman MG; Underwood AJ (1995) Mangrove forests. In: Underwood AJ, Chapman MG (eds) Coastal marine ecology of temperate Australia. University of New South Wales Press, Sydney, p 187-204

Connell JH (1961) Effects of competition, predation by Thais lapillus, and other factors on the distribution of the barnacle Balanus balanoides. Ecol Monogr 31:61-104

Connell SD, Jones G.P (1991) The influence of habitat complexity on postrecruitment processes in a temperate reef fish population. J Exp Mar Biol Ecol 151:271-294

Crisp DJ, Barnes H (1954) The orientation and distribution of barnacles at settlement with particular reference to surface contour. J Anim Ecol 23:142-162
Crowe T (1996) Different effects of microhabitat fragmentation on patterns of dispersal of an intertidal gastropod in two habitats. J Exp Mar Biol Ecol 206:83-107

Dean RL, Connell JH (1987) Marine invertebrates in an algal succession. II. Tests of hypotheses to explain changes in diversity with succession. J Exp Mar Biol Ecol 109. $217-247$

Downes BJ, Lake PS, Schreiber ESG, Glaister A (1998) Habitat structure and regulation of local species diversity in a stony, upland stream. Ecol Monogr 68:237-258

Emson RH, Faller-Fritsch RJ (1976) An experimental investigation into the effect of crevice availability on abundance and size-structure in a population of Littorina rudis (Maton): Gastropoda: Prosobranchia. J Exp Mar Biol Ecol 23:285-297

Fairweather PG (1988) Movements of intertidal whelks (Morula marginalba and Thais orbita) in relation to availability of prey and shelter. Mar Biol 100:63-68

Fletcher WJ, Underwood AJ (1987) Interspecific competition among subtidal limpets: effects of substratum heterogeneity. Ecology 68:387-400

Fryer JG (1983) Stereoscopic coral maps from underwater photogrammetry. Cartographic J 20:23-25

Gause GF (1934) The struggle for existence. Hafner, New York

Gee JM, Warwick RM (1994a) Metazoan community structure in relation to the fractal dimensions of marine macroalgae. Mar Ecol Prog Ser 103:141-150

Gee JM, Warwick RM (1994b) Body-size distribution in a marine metazoan community and the fractal dimensions of macroalgae. J Exp Mar Biol Ecol 178:247-259

Grinnell J (1917) The niche-relationships of the California thrasher. Auk 34:427-433

Gunnarsson B (1992) Fractal dimension of plants and body size distribution in spiders. Funct Ecol 6:636-641

Hart DD (1978) Diversity in stream insects: regulation by rock size and microspatial complexity. Proc Int Assoc Theoretical and Applied Limnology (Verhandlungen) 20: $1376-1381$

Heck. KL Jr, Crowder LB (1991) Habitat structure and predator-prey interactions in vegetated aquatic systems. In: Bell SS, MCCoy ED, Mushinsky HR (eds) Habitat structure: the physical arrangement of objects in space. Chapman and Hall, New York, p 282-299

Hills JM, Thomason JC (1996) A multi-scale analysis of settlement density and pattern dynamics of the barnacle Semibalanus balanoides. Mar Ecol Prog Ser 138:103-115

Huffaker CB (1958) Experimental studies on predation: dispersion factors and predator-prey oscillations. Hilgardia 27:343-383

Hutchings P, Saenger P (1987) Ecology of mangroves. University of Queensland Press, St. Lucia

Huynh H, Feldt LS (1970) Conditions under which mean square ratios in repeated measurements designs have exact F-distributions. J Am Stat Assoc 65:1582-1589

Jacobi CM, Langevin R (1996) Habitat geometry of benthic substrata: effects on arrival and settlement of mobile epifauna. J Exp Mar Biol Ecol 206:39-54

Jeffries M (1993) Invertebrate colonization of artificlal pondweeds of differing fractal dımension. Oikos 67:142-148

Kaly UL (1988) Distribution, abundance and size of mangrove and saltmarsh gastropods. Dissertation, University of Sydney

Keough MJ, Downes BJ (1982) Recruitment of marine invertebrates: the role of active larval choices and early mortality. Oecologia (Berl) 54:348-352

Keough MJ, Quinn GP, Bathgate R (1997) Geographic varia- 
tion in interactions between size classes of the limpet $\mathrm{Cel}$ lana tramoserica. J Exp Mar Biol Ecol 215:19-34

Kostylev V. Erlandsson. J, Johannesson K (1997) Microdistribution of the polymorphic snail Littorina saxatilis (Olivi) in a patchy rocky shore habitat. Ophelia 47:1-12

Lemire M. Bourget E (1996) Substratum heterogeneity and complexity influence micro-habitat selection of Balanus sp. and Tubularia crocea larvae. Mar Ecol Prog Ser 135: $77-87$

Loder N, Blackburn TM, Gaston KJ (1997) The slippery slope: towards an understanding of the body size frequency distribution. Oikos 78:195-201

Luckhurst BE, Luckhurst K (1978) Analysis of the influence of substrate variables on coral reef fish communities. Mar Biol 49:317-323

McCormick MI (1994) Comparison of field methods for measuring surface topography and their associations with a tropical reef fish assemblage. Mar Ecol Prog Ser 112: $87-96$

McCoy ED, Bell SS (1991) Habitat structure: the evolution and diversification of a complex topic. In: Bell SS, McCoy ED Mushinsky HR (eds) Habitat structure: the physical arrangement of objects in space. Chapman and Hall, New York, p 3-27

McGuinness KA, Underwood A.J (1986) Habitat structure and the nature of communities on intertidal boulders. J Exp Mar Biol Ecol 104:97-123

Moran MJ (1985) The timing and significance of sheltering and foraging behaviour of the predatory intertidal gastropod Morula marginalba Blainville (Muricidae). J Exp Mar Biol Ecol 93:103-114

Morse DR, Lawton JH, Dodson MM, Williamson MH (1985) Fractal dimension of vegetation and the distribution of arthropod body lengths. Nature (Lond) 314:731-733

Raffaelli DG, Hughes RN (1978) The effects of crevice size and availability on populations of Littorina rudis and Littorina neritoides. J Anim Ecol 47:71-83

Sanson GD, Stolk R, Downes BJ (1995) A new method for characterizing surface roughness and available space in biological systems. Funct Ecol 9:127-135

Shorrocks B, Marsters J, Ward I, Evennett PJ (1991) The fractal dimension of lichens and the distribution of arthropod body lengths. Funct Ecol 5:457-460

Simberloff D, Berthet P, Boy V, Cousins SH, Fortin MJ, Goldburg R, Lefkovitch LP, Ripley B, Scherrer B, Tonkyn D (1987) Novel statistical analyses in terrestrial animal ecology: dirty data and clean questions. In: Legendre $P$, Legendre L (eds) Developments in numerical ecology. Springer-Verlag, Berlin, p 559-572

Sokal RR, Rohlf FJ (1981) Biometry, 2nd edn. WH Freeman and $\mathrm{Co}$, New York

Stoner AW, Lewis FG III (1985) The influence of quantitative and qualitative aspects of habitat complexity in tropical sea-grass meadows. J Exp Mar Biol Ecol 94:19-40

Editorial responsibility: Roger Hughes (Contributing Editor), Bangor, United Kingdom
Sugihara G, May RM (1990) Applications of fractals in ecology. Trends Ecol Evol 5:79-86

Sun B. Fleeger JW, Carney RS (1993) Sediment microtopography and the small-scale spatial distribution of meiofauna. J Exp Mar Biol Ecol 167:73-90

Underwood AJ (1975a) Comparative studies on the biology of Nerita atramentosa Reeve. Bembicium nanum (Lamarck) and Cellana tramoserica (Sowerby) (Gastropoda: Prosobranchia) in S.E. Australia. J Exp Mar Biol Ecol 18: $153-172$

Underwood AJ (1975b) Intertidal zonation of prosobranch gastropods: analysis of densities of four coexisting species. J Exp Mar Biol Ecol 19:197-216

Underwood AJ (1978) An experimental evaluation of competition between three intertidal prosobranch gastropods. Oecologia (Berl) 33:185-202

Underwood AJ (1984) Vertical and seasonal patterns in competition for microlagae between intertidal gastropods. Oecologia (Berl) 64:211-222

Underwood AJ (1997) Experiments in ecology: their logical design and interpretation using analysis of variance. Cambridge University Press, Cambridge

Underwood AJ, Barrett $G(1990)$ Experiments on the influence of oysters on the distribution, abundance and sizes of the gastropod Bembicium auratum in a mangrove swamp in New South Wales. J Exp Mar Biol Ecol 137:25-45

Underwood A.J, Chapman MG (1989) Experimental analyses of the influences of topography of the substratum on movements and density of an intertidal snail, Littorina unifasciata. J Exp Mar Biol Ecol 134:175-196

Underwood A.J, Chapman MG (1992) Experiments on the topographic influences on density and dispersion of Littorina unifasciata in New South Wales. In: Mill PJ, Reid DG (eds) Proc 3rd Int Symp Littorinid Biology. The Malacological Society of London, London, p 181-195

Underwood AJ, Chapman MG (1996) Scales of spatial patterns of distribution of intertidal invertebrates. Oecologia (Berl) 107:212-224

Walters LJ, Wethey DS (1996) Settlement and early post-settlement survival of sessile marine invertebrates on topographically complex surfaces: the importance of refuge dimensions and adult morphology. Mar Ecol Prog Ser 137: 161-171

Warren JH, Underwood AJ (1986) Effects of burrowing crabs on the topography of mangrove swamps in New South Wales. J Exp Mar Biol Ecol 102:223-235

Williamson MH, Lawton JH (1991) Fractal geometry of ecological habitats. In: Bell SS, McCoy ED, Mushinsky HR (eds) Habitat structure: the physical arrangement of objects in space. Chapman and Hall. New York, p 69-86

Winer BJ, Brown DR, Michels KM (1991) Statistical principles in experimental design, 3rd edn. McGraw-Hill Book Company, New York

Submitted: February 7, 1998; Accepted: May 22, 1998

Proofs received from author(s): July 7, 1998 